\title{
Variations
}

Variations

Revue internationale de théorie critique

$23 \mid 2020$

Pour une gauche érotique

\section{Mélancolie de gauche}

A propos du récent recueil de poésie d'Erich Kästner (1931)

\section{Walter Benjamin}

Traducteur : Alexander Neumann

\section{OpenEdition}

Journals

Édition électronique

URL : http://journals.openedition.org/variations/1382

DOI : 10.4000/variations. 1382

ISSN : 1968-3960

Éditeur

Les amis de Variations

Référence électronique

Walter Benjamin, « Mélancolie de gauche », Variations [En ligne], 23 | 2020, mis en ligne le 01

septembre 2020, consulté le 07 septembre 2020. URL : http://journals.openedition.org/variations/ 1382 ; DOI : https://doi.org/10.4000/variations.1382

Ce document a été généré automatiquement le 7 septembre 2020.

Les ami•e•s de Variations 


\title{
Mélancolie de gauche
}

\author{
A propos du récent recueil de poésie d'Erich Kästner (1931)
}

\author{
Walter Benjamin
}

Traduction : Alexander Neumann

\section{NOTE DE L'ÉDITEUR}

Texte de Walter Benjamin écrit en 1931 en allemand, voir: http://

www.glanzundelend.de/Artikel/abc/b/benjamin_melancholie.htm (pour la version print allemande W.Benjamin, Kritiken und Rezensionen, Band 13, Suhrkamp)

1 Les poèmes de Kästner prennent aujourd'hui la forme éditoriale de trois volumes imposants. Les curieux qui voudraient aller au fond du caractère de ces strophes ont tout à gagner de se tourner vers leur forme de publication initiale. Rangés dans des livres, les strophes se tiennent serrés, d'une façon un peu étouffante, alors qu'elles filent comme des poissons dans l'eau à travers les quotidiens. Une eau parfois trouble, traversée d'un tas de détritus, qui bénéficie à l'auteur, car ses poissonnets poétiques ont pu y grandir et s'engraisser.

2 La popularité de ces poèmes est liée à l'ascension sociale d'une couche de parvenus, qui sans gêne aucune a pris possession de positions de pouvoir dans l'économie, et qui se complait comme nulle autre dans la mise à nu, l'affichage sans masque de sa propre physionomie économique. Il serait faux de croire que cette couche, qui ne visait rien d'autre que la réussite, et qui ne reconnait rien d'autre, aurait véritablement conquis des positions dominantes. Son idéal était bien trop asthmatique pour y parvenir. Un idéal d'agents sans descendance, qui ont émergé d'une condition insignifiante, qui n'avaient pas la force de prendre leurs dispositions familiales pour les décennies à venir, à la manière des grands banquiers, mais qui voyaient à peine plus loin que la fin d'une saison et qui ne se souciaient que d'eux-mêmes. Qui ne les aurait pas déjà vu: leurs yeux rêveurs de bébé derrière leurs lunettes à monture en corne, leurs larges joues blafardes, leurs voix trainante, le fatalisme de leur gestes et de leur mode de pensée. Dès l'origine, notre poète s'adresse exclusivement à cette seule couche, pour lui 
plaire, en lui tendant le miroir ou plutôt en lui rapportant un miroir, du matin au soir. Les écarts entre ses strophes rappellent les plis graisseux de leurs nuques, ses rimes sont leurs lèvres en saucisses, ses césures sont les petits creux de leur chair, ses chutes sont les pupilles de leurs yeux.

Cette couche ne goute qu'un éventail thématique réduit et montre une attention limitée, alors que Kästner n'est jamais en mesure de toucher les dépossédés avec ses envolées rebelles ou de frapper les industriels avec son ironie. Cela est le cas parce que cette lyre conserve avant tout - malgré ses apparences - les intérêts corporatistes d'une couche intermédiaire: agents, journalistes, chefs du personnel. La haine, que sa lyre proclame à l'encontre de la petite bourgeoisie aisée, dénote cependant elle-même un accent petit-bourgeois, un peu trop intimiste. La même position perd rapidement en force de frappe face à la grande bourgeoisie, avant d'avouer son désir du mécène en un râle :

"Ô, si seulement nous avions une douzaine de sages, pourvus de très grandes sommes d'argent" (o gäbe es nur ein Dutzend Weise, mit sehr viel Geld).

Cela n'étonnera personne que Kästner affiche une familiarité tordue qui va de pair avec une manière de voir l'économie de travers, lorsqu'il il veut régler son compte aux banquiers dans un "Hymne", ou quand il présente les réflexions nocturnes d'une femme prolétarienne sous le titre "Une mère tire son bilan". A la fin, le foyer et la retraite sont les bandes passantes le long desquelles une classe supérieure poursuit le poète, trituré et harcelé.

Ce poète est mécontent, déprimé même. Son côté dépressif résulte pourtant de sa propre routine. Car céder à la routine signifie de sacrifier toute idiosyncrasie, de lâcher le talent qui permet de ressentir la nausée. Ce sont des circonstances qui présentent quelques traits de similarité avec le cas Heine. Routinières sont les remarques que Kästner enfonce pour rendre inégales ses poèmes, afin de donner une apparence de balle de rugby à ces baballes laquées pour enfants. Et rien n'est plus routinier que l'ironie qui sert de levain à une opinion privée, à la façon d'une préparation qui permet de réussir une pate. Quel dommage que son impertinence se place tellement hors sujet, en rapport aux courants idéologiques et forces politiques dont dispose l'auteur. Rien ne trahit mieux à quel point la position de cette intelligentsia gauchiste est perdue que sa sous-estimation grotesque de l'ennemi, qui fournit le prétexte de ses attaques. Tout cela a peu de choses à voir avec le mouvement ouvrier. Bien au contraire, ce phénomène révèle la décomposition bourgeoise qui correspond à ce mimétisme féodal qui reconnaissait l'empire Prusse en la personne de l'officier de réserve. Les écrivains du genre d'un Kästner, d'un Mehring ou d'un Tucholsky manifestent un mimétisme prolétarien de la bourgeoisie en voie de décomposition. La fonction de cette intelligentsia est d'engendrer, sur le plan politique, des coteries au lieu de partis, des modes à la place d'Ecoles, du point de vue littéraire, des agences à la place de producteurs, d'un point de vue économique. Ce qui se montre dans le fait que pareille intelligentsia de gauche a servi de véhicule à toutes les tendances spirituelles, sans interruption depuis 15 ans, depuis l'Activisme en passant par l'expressionisme, jusqu'à la nouvelle objectivité (Neue Sachlichkeit). La signification politique de la mouvance s'ensable pourtant dans la traduction d'une réactivité révolutionnaire qu'une partie de la bourgeoisie a pu manifester jadis, et qui s'exprime dans des éléments de divertissement, d'amusement, qui peuvent faire l'objet d'une consommation. 
6 A travers ce type d'approche, l'Activisme a su imposer à la dialectique révolutionnaire le visage d'un bon sens dépourvu de toute condition de classe. C'était en quelque sorte la journée des portes ouvertes de l'hebdomadaire des ces intellectuels. A son tour, l'expressionisme a exposé le geste révolutionnaire, le bras levé, le poing fermé, dans une version en papier mâché.

7 Que découvre "l'élite spirituelle" lorsqu'elle entreprend l'inventaire de ses affects? Ses propres sentiments peut-être? Ils ont été bradés depuis longtemps déjà. Tout ce qu'il en reste sont des espacements, à l'endroit de leur coeur soyeux où les sentiments ont du résider un jour - touchant la nature, l'amour, la passion et l'humanité. A présent, l'on caresse mécaniquement les creux qui se trouvent à la place. Leur ironie pédante croit avoir gagné quelque chose en troquant ces schèmes contre l'objet lui-même, mettant grandement en scène sa pauvreté pour s'enivrer du vide abyssal. Car l'aspect nouveau de cette objectivité, c'est la manière de se régaler des biens culturels passés, comme le bourgeois est repu de ses biens matériels. Jamais encore on s'est installé d'une manière si confortable dans une situation inconfortable. Bref, ce radicalisme de gauche désigne exactement une attitude qui ne correspond plus à aucune action politique. Ce radicalisme se place à gauche, non pas de telle ou telle autre ligne précise, mais il se place tout simplement à gauche du possible. Sachant que, dès le début, il n'ambitionne rien d'autre que de se satisfaire lui-même, de jouir d'un repos fait de refus. Le dernier tube de ces publications, c'est de transformer la lutte politique, changeant la nécessité de prendre une décision en une source de plaisir, tournant le moyen de production en objet de consommation. Kästner, doté d'un grand talent, maitrise à la perfection toute la gamme de cette littérature. Avant tout, il affiche une attitude dont la marque se retrouve dans de nombreux titres de ses poèmes. Il y a un "Eloge aux oeufs", un "Chant de Noël nettoyé à sec", le "Suicide à la piscine publique", le "Destin d'un Noir imaginaire", etc. Pourquoi tant de contorsions corporelles? Sans doute parce que la prise de conscience et la critique sont à portée de main; mais elles joueraient les trouble-fêtes et doivent donc être réduit au silence à tout prix. Le poète se sent ainsi obligé de les bâillonner, ce qui qu'il fait que leurs spasmes désespérés provoquent l'effet qu'un contorsionniste espère obtenir, grâce à ses tours, celui d'égayer un large public qui n'a pas un gout très sûr. Dans la littérature de Morgenstern, le non-sens n'était que l'envers d'une fuite dans la théosophie. Le nihilisme de Kästner, en revanche, n'occulte plus rien, un peu comme un gosier qui est tellement en train de bayer qu'il ne peut plus se refermer.

\section{INDEX}

Mots-clés : Théorie critique, Ecole de Francfort, lutte des classes, Erich Kästner, mélancolie de gauche 
AUTEURS

\section{WALTER BENJAMIN}

Walter Benjamin fut une figure centrale de la Théorie critique 